\title{
"Burn the witch": The impact of the fear of witchcraft on social cohesion in South Africa
}

\section{Abstract}

This paper explores beliefs about witchcraft in a sample of community members in South Africa with the aim of showing that the fear of bewitchment dislocates important linkages and networks between people. This is most evident in relation to the violent consequences associated with witchcraft, particularly affecting those who are accused. Interviews with community members in South Africa provide us with a context to understand the emotional response discourses that witchcraft opens. This allows comments on how witchcraft beliefs are fused with fear, which mobilises community members towards behaviour against those accused. As a consequence, violent behaviour becomes an acceptable outlet in coping with witchcraft accusations. It is argued that increased distrust amongst community members related to witchcraft leads to tension and interpersonal conflict, therefore breaking down networks essential to ensuring harmony.

\section{Introduction}

It is assumed in many parts of the world that witchcraft beliefs have given way to westernisation but in Sub-Saharan Africa, the belief in witchcraft is widely held (Miguel, 2005). Serving a variety of purposes, belief in witchcraft and the supernatural has shown no tendency to lose its salience (Moore \& Sanders, 2001). Of course, in contexts where belief regarding these religio-cultural expressions abound, people are unlikely to acknowledge violent encounters that emerge from the belief as violence (Douki, Nacef, Belhadj, Bouasker \& Ghachem, 2003), but rather as a necessity to protect community well-being.

\section{Yaseen Ally}

Department of Psychology, Nelson Mandela Metropolitan University (NMMU), Port Elizabeth yaseen.ally@nmmu.ac.za

\section{Keywords:} witchcraft, witchcraft accusations, violence, fear, social cohesion, mob violence, gender based violence, violence against women 
The violence associated with witchcraft, described in various texts (Barstow, 1995; Levack, 1995; Briggs, 2002; Stark, 2003) found expression in a video that was anonymously sent to the researcher (unknown author, witchcraft-related violence, video, 2009). This video showed a group of people, chanting and screaming while a fire burnt in broad day light. Images from the video appear below:
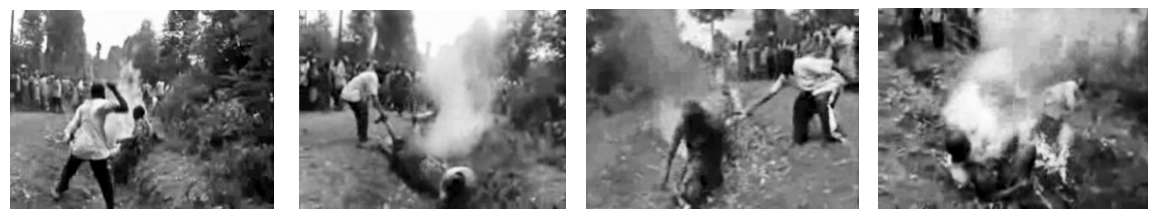

The chanting and screaming of the group were foreshadowed by the screams of accused "witches" burning (Unknown Author, witchcraft-related violence, 2009). These persons tried fleeing the violence but members from the group kept kicking them and dragging them back into the fire. A man from the group is seen running and kicking one of the accused, while the group cheers him on. Another man, having cut a thick branch from a tree, beats a second accused repeatedly and severely all over the body and head. The end result of this witch-hunt, most likely, results in death for the accused.

The video and pictures obtained alludes to two important points. Firstly, violence may be the outcome faced by those accused of witchcraft. This simple deduction has seen to the persecution of many people throughout history (Burne, 1914; Maxwell-Stuart, 2005), in some of the most brutal expressions known to humanity.

The second consideration stemming from the video and various pictures received and also documented in witchcraft texts, is that the violence faced by the accused is mob-based. Rose (1982: 142) for example, supports this observation, indicating that the threat posed by "evil-doers" like witches creates the condition to mobilize an "effective collective action against a group of such enemies". Indicative of this, is that once an accusation has been made, the fear of bewitchment mobilises a community to protect itself from potential harm. Baroja (1964) emphasised the importance of understanding witchcraft from the perspective of those who believe in it. Baroja (1964: xiii) states, "much more is known about witchcraft from the point of view of those who believe in witches ... and we have to analyse the mentalities of ... whole communities gripped by a specific fear ...."

The understanding of the belief in witchcraft and the supernatural becomes even more urgent in light of the violent consequences faced by those accused of witchcraft. In 
evaluating the $17^{\text {th }}-18^{\text {th }}$ century witch hunts in Europe and America (Evans-Pritchard, 1931; Harwood, 1970; Larner, 1974), as well as recent studies in South Africa (Bornman, van Eeden \& Wentzel, 1998), it becomes clear that witchcraft accusations often manifests in violent consequences and are still a current reality in some contexts. From burning to drowning, stoning and being hacked, those accused of witchcraft meet with torture and death (Hole, 1914; Bornman, van Eeden \& Wentzel, 1998; Roy, 1998; Briggs, 2002; Stark, 2003). It must be noted that witchcraft accusations are not always faced with physical violence. Sometimes, when suspicions arise, witchcraft may be fought within the spiritual realm and muthi (medicine for a variety of physical, psychological and spiritual ailments made from natural elements) from a traditional healer may be used (on the body, in the home, in business) to protect oneself. At times, a traditional healer may be consulted, to counter the effects of witchcraft by sending the affliction back to those suspected for the misfortune being experienced.

In this paper, we locate witchcraft beliefs from within the reality and perspectives provided by community members in South Africa. Insight into how witchcraft is understood within a particular reality, which creates the framework within which violence is directed at those accused of the craft, will be gained. Specifically, the paper argues that witchcraft accusations provide the space for the creation of tension, interpersonal conflict and distrust, thus breaking down important social linkages and networks essential in ensuring harmonious community functioning. The manifest violent consequences of witchcraft accusations, it is argued, is a direct consequence of the depletion of social capital and cohesion. The implications for violence prevention interventions is also explored, with the aim of commenting on the importance of social cohesiveness to their success.

\section{The belief in witchcraft}

Any investigation of witchcraft must consider its origins. Many religions and various cultures incorporate supernatural beliefs like spirit possession, the Devil, angels and of course witchcraft (Ashour, 1993; Dein, 2003; Eldam, 2003; Abdussalam-Bali, 2004; Stafford, 2005). Many African cultures and religions believe in supernatural forces too, including spells, invisible forces, ancestral spirits and ditlhare, moriane or umuti (meaning medicine with magical powers) (Meyer, Moore \& Viljoen, 2003; Mkhize, 2004; Ivey \& Myers, 2008a). These beliefs in supernatural forces become a part of the everyday worldviews held by an individual or a community. Swartz (2002) says that the belief in supernatural entities stemming from religious or cultural texts and unwritten stories, are transposed to the relations people forge with others and provides one with a model of health, illness and misfortune. Fortes (1953) contended that witchcraft is an ideology for daily living. The belief in witchcraft thus derives its existence from religious and cultural systems that allow for the larger belief in the influence from supernatural entities. 
To simplify the understanding of witchcraft ${ }^{1}$, which is dense, we categorise it into three types. The first type of witchcraft refers to the capacity of some individuals to manipulate objects in nature as well as through incantations, charms and spells to harm others. Larner (1974) informs us that this form of witchcraft is released through power activated by hatred. Interpersonal quarrels, jealousy at the success of others and even beauty may thus be motivating factors to harm another person (Evans-Pritchard, 1937; Fortes, 1953).

The second type of witchcraft is steeped in a religious tradition where a pact is taken with the Devil or Satan, a Christian fallen angel associated with evil. Here, witches, the users of witchcraft, are believed to engage in sexual relations with the Devil in exchange for supernatural powers, which they use to harm their enemies (Heinemann, 2000; Parrinder, 1963).

The third type of witchcraft, very similar to the first is reflective of a community of evil. In this community, witches share common goals, assist each other in harming enemies and even combine forces to harm others (Levack, 1995). Implicit to the third type of witchcraft is that witches form a cult and can teach their children the art of magic (Briggs, 2002). Based on these definitions, it seems that the belief in witchcraft is more often characterized by fantasy and the supernatural and even though these definitions were defined separately, they are intertwined in reality.

In accordance with the three categories outlined above, witches are believed to have the capacity to fly at night and to transform themselves into animals of their choice (Burne, 1914; Hole, 1939; Joshi, 2000). They are believed to behave in eerie ways, and with their fierce stares able to bring bad luck, pain and other undesirable consequences on others (Igwe, 2004; Evans-Pritchard, 1937). Bodin, a French demonologist of the late $16^{\text {th }}$ century, famous for his witch hunting guide said that witches promised Satan babies still in the womb, drank human blood, and ate human flesh. Witches themselves are also fantastically associated with flying, attending witches' meetings in the nude, shape-shifting and terrifying their enemies (Simmons, 1980). Physiologically, for example, witches can cause loss of hearing, speech and sight; loss of memory; terrifying hallucinations and even actual markings, sores and bruises on the skin; sickness, illness and even death (Briggs, 2002; Hansen, 1969).

In South Africa, witches, commonly referred to in seSotho as baloi (plural) or moloi (singular) or in isizulu as umthakathi (singular) or abathakati (plural), use magic potions known as korobela, which can cause a person to fall in love, regardless of

We have excluded those definitions of "white" witchcraft, considered the binary opposite of "black" witchcraft. White witchcraft has the capacity to allow for a bewitched person to be cured (see, Levack, 1995; Barstow, 1996; Briggs, 2002). Our exclusion is based on focusing our aim on those connotations of witchcraft which may feed into violence. 
their own true inclinations; while intelezi, can cause a person to become violent (Ashforth 2000). Isidliso is also thought to wreak all sorts of social misfortunes and divorce, unemployment, unpopularity, family conflict, as well as physical illness and death are regarded within the domain of the witches' capacity. In fact, HIV/ AIDS is also viewed as a manifestation of bewitchment in South Africa and other African countries, like Zimbabwe (Van Dyk, 2001). The notion of "zombies", or people controlled by a witch to do their evil, is also widespread in contemporary South Africa (Comaroff \& Comaroff 1999; Niehaus 2000). Another closely linked phenomenon, is the belief in the tokoloshe. The tokoloshe created by witches, is believed to have the capacity to cause illness and death on the command of the witch (McNab, 2007). Peltzer and Renner (2003) for example, explored taxi drivers perceptions of the causes of accidents and the tokoloshe, sent by witches was cited as a dominant factor.

On the basis of these descriptions, witchcraft seems to represent a theory of misfortune. This theory of misfortune guides the interactions between people and provides them with explanations, steeped in the supernatural, for almost every misfortune. Evans-Pritchard (1937) argues in this vein that witchcraft may be drawn upon as an explanatory frame in light of what may be considered by the person as undeserved misfortunes. Regardless though, of the role witchcraft may play in deflecting responsibility for misfortunes, the capacity witchcraft is believed to possess, manifests in a sense of fear.

As supported by Webster (1932: 486), we understand that in communities where witchcraft beliefs abound, "a man is likely to die if he believes himself bewitched ... the man may be strong and healthy; nevertheless he falls into a decline and soon expires ..." Morton-Williams (1960) alludes to this point and informs us that the Yoruba admit they fear witchcraft more than anything else as it is believed to be the most frequent cause of death. Oliver (1928: 117) states that witches are "believed to haunt and worry their victims in their own homes, though they remained invisible and were in reality found asleep in their own beds when investigations were made". Hansen (1969: 11) explicitly indicates that the hysterical symptoms presented by victims of witchcraft "was not witchcraft itself but the victim's fear of it".

In light of this, it follows that fear is embedded in the belief in witchcraft, as it contains supernatural power to negatively influence any aspect of one's life. This is an important consideration, given that the fear of witchcraft may be a strong motivating factor that contributes to the violent consequences associated with such accusations. In this instance then, social cohesion may be directly impacted by increased fear of being bewitched. 


\section{Fear of witchcraft and social cohesion}

Any discussion of social cohesion must take into account social capital. Bourdieu (1986) defined social capital as the aggregate of the actual or potential resources which are linked to possession of a durable network of more or less institutionalized relationships of mutual acquaintance and recognition - or in other words, to membership in a group - which provides each of its members with the backing of the collectively-owned capital. Putnam's (1993: 36) seminal work on social capital elaborates on the nature of social relations, and he suggested that social capital consists of "the features of social organization, such as networks, norms, and trust that facilitate coordination and cooperation for mutual benefit". Dayton-Johnson (2003) and Lin \& Erickson (2008) provide more recent definitions of social capital that reflects the same ideas. Dayton-Johnson (2003) defines social cohesion is a characteristic of society which depends on accumulated social capital. Lin and Erickson (2008) state that social capital focuses on the production and the returns of social capital. They further state that social capital explicates how collective actors and individuals invest in social relations through which access to diverse and rich resources are gained. Based on these definitions, social capital is considered the result of investments in social relations that are made by individuals and particular groups that have returns, which may be monetary or otherwise. One important aspect of almost all the definitions of social capital is the fact that social capital, similar to physical or human capital, is (explicitly or implicitly) developed by individuals to generate some future returns. In this sense, social capital is considered as a resource and not just a component of social structures. This idea is expressed by Coleman (1990) who states that the function identified by the concept of "social capital" is the value of certain aspects of social structure to actors, as resources that can be used by the actors to realize their interests. He further adds that like other forms of capital, social capital is productive, making possible the achievement of certain ends that would not be attainable in its absence.

Social capital, it is argued, is a resource that increases rather than decreases with use. To this end, communities with norms of reciprocity, which in turn reinforces sentiments of trust may experience positive economic development and effective governments (Putnam, 1993). Social capital then, creates the condition for social cohesion to develop and for coordination and cooperation for mutual benefit to occur. It follows that if social capital is high, then the level of cohesiveness amongst community members may in turn, be healthy. Social cohesion is defined as a characteristic of society which depends on the accumulated social capital (Dayton-Johnson, 2003).

While Putnam (1993) argues that social capital is manifested in various forms of pro-social local associations, it becomes more evident to us when social capital may be on the decrease, expressed through increased social tension, violent crime and the targeting of 
minorities. The formation of gangs, for example, may be considered a form of "negative" or detrimental form of social cohesion, what Putnam (2000) called bonding form of social cohesion. Putnam (1993) argues that social capital can contribute to social cohesion but it cannot be assumed that it automatically leads to social cohesion.

Violent conflict then, can be understood as stemming from a relationship between social capital and violent conflict, mediated by social cohesion (Colleta \& Cullen, 2000). According to them, "the weaker the social cohesion, the weaker the reinforcing channels of socialization and social control" (Colleta \& Cullen, 2000: 4). From this, it can be drawn that healthy social relations and networks, between people, groups and organisations enables the development of "positive" social cohesion, or trusting relationships, which essentially is an expression of the social capital of that community.

Witchcraft accusations however, allude to the opposite - social relations that are disharmonious. In light of the belief that bewitchment generally causes harm distrust amongst people in communities where the belief exists can be expected. For example, Golooba-Mutebi (2005) says that community members are afraid to trust friends and neighbours who may turn against each other - if accusations of witchcraft are drawn into those interpersonal spaces. In this way then, social cohesion begins to break down as the trust between people is compromised. The result of these damaged networks is fear, which manifests in interpersonal conflict, suspicion and violence. Therefore as suggested by Beauvais and Jenson (2002) social cohesion can operate both as an independent and dependant variable. In this case, fear of witchcraft breaks down social cohesion and in turn this breakdown of social cohesion leads to greater levels of tension and mistrust, which creates the conditions in which accusations of witchcraft increase. In light of this, it is argued that in communities where the belief in witchcraft permeates and influences the thinking of people, that social cohesion is negatively affected by the fear emanating from the belief in witchcraft's malevolence. It is this fear that has a direct impact on social relations within the community. Putnam (2000) refers to bonding social capital that tends to reinforce exclusive identities and homogenous groups (Putnam, 2000). Bonding social capital may provide an in-group consciousness for group members, while excluded individuals may be negatively targeted. Attempts therefore, to understand and essentially prevent witchcraft violence, like any form of violence, may thus be compromised if an understanding of the importance of social cohesion is not considered.

\section{Violence prevention interventions}

Violence prevention interventions specific to witchcraft accusations in South Africa are rare. This is not too much of a surprise, even in light of the increasing reports of witchcraft violence in various communities. One may consider that this silencing of one expression 
of violence is located in the fact that the belief cuts through every element of African life and that many people are afraid of the inherent power of witchcraft. For example, Fisiy \& Geschiere (1991) indicate that witchcraft is at the centre of politics. This thought links to the fact that in South Africa, politicians, whose views hold sway over many people, have indicated that witchcraft may be relied upon to maintain power (Kgosana, 2009). The implication of this is that the belief which penetrates all elements of social and private life is being given added strength in political life and this gives power to the fear of bewitchment.

Therefore, rather than a focus on the issue itself - violence - focus is given to the extraordinary, supernatural and 'evil' capacity inherent to those accused of witchcraft. It suffices then, that any intervention aimed at addressing this expression of violence, must be located within the context of such beliefs.

A lack of such understanding may manifest in inappropriate ideas and actions. For example, The Mpumalanga Witchcraft Suppression Act in South Africa calls for an end to the belief in witchcraft (1957). The Act prohibits various activities related to witchcraft, witch-hunting and fines and imprisonment are likely consequences. One has to consider if a belief in any entity can be legislated out of social life. Thus, the call to an end to witchcraft belief implies a lack of understanding of the function the belief serves and takes away the impetus of a focus on the problem itself - the interpretation of beliefs. These interpretations are important as they allow for violent expressions that are the outcome of distrust and damaged interpersonal relations.

In this paper, we explore community members understanding of witchcraft, with a view to commenting on the fear emanating from the belief. We locate this understanding in relation to social cohesion, arguing that a breakdown in important linkages within communities may manifest in violent outcomes.

\section{Methodology}

\section{Sample}

The project within which the data collection occurred, provided the researcher with a base to develop relationships with various community stakeholders. Through these relations, the researcher gained excess to the participants. Participants were all from semi-rural communities, South of Johannesburg. In total, 29 participants took part in the study. Three focus group discussions were conducted. These groups comprised of 12, 4 and 6 people (22 participants). The numbers in the groups were not planned but rather, developed as a snowball effect. Additionally, 7 non-structured conversations were held with individual community members, bringing the total number of participants to 29 . Non-structured conversations were chosen as the data collection tool, as it allowed participants to bring their understanding of the belief in witchcraft. 


\section{Data analysis}

Banyard and Miller (1998) state that qualitative methods are a powerful set of tools enabling researchers to understand the subjective meanings people make of their experiences and which gives rise to specific behaviours. Given this and in light of our aims, the qualitative approach is best suited to gather the depth of understanding needed from the participants of the study.

Thematic content analyses of the transcribed interviews was used as a technique as it allowed for relevant issues to be highlighted through the identification of themes (Henning, 2004; Babbie \& Mouton, 2005). This enabled the researcher to formulate an overall understanding of the meanings of witchcraft presented by the participants. Greenwood, Hussain, Burns and Raphael (2000) also suggest that this analytical tool allows the researcher to elicit the depth and detail required.

\section{Limitations}

The sample size was too small to draw broad conclusions. Further studies are required to determine the broader influence of witchcraft beliefs on social cohesion in South Africa. The study does not localise witchcraft beliefs within specific provinces of South Africa. Research into the possible provincial differences in the belief in witchcraft may enable deeper nuances of the belief.

\section{Results and discussion}

The following section presents the findings of the study. We present three themes produced from the thematic content analysis. These are: (i) descriptions and capacity of witches: the belief in witchcraft (ii) the fear of witchcraft, and (iii) violence and witchcraft accusations.

\section{Descriptions and capacity of witches: The belief in witchcraft}

Witchcraft as a theory of misfortune provides an explanatory framework for almost every social, psychological, economic and health-related experience in contexts where the belief is real (Niehaus, 1993; Levack, 1995). Participants reflected perspectives of witchcraft as a theory of misfortune. Interestingly, participants seemed surprised when asked "what is witchcraft?" However, they were able to present perspectives of witchery when the terms "molo", "abathakat" or even "umuthi" were used.

"It is the control and manipulation of people, things and events for a negative outcome in life. It is also a form to get back at people, or make one do something they would not ordinarily do or practice. It causes dysfunction."

"They make your life upside down, they do it with muthi, they get it from the floor most of the muthi the people they know." 
"You sometimes you fight with your husband ... they throw something by your house everything go upside down."

"Maybe you are doing something like a business your business is going up ... they can make people not come to your store."

"They maybe use the muthi to maybe destroy other people's life."

"Maybe they say she mustn't have a boyfriend she mustn't have a man just like that ... all her children all her family mustn't have a good life."

These perspectives reflect the understanding that witchcraft can cause negative outcomes or experiences in one's life. From business misfortune, indicating socio-economic issues, to interpersonal quarrels and jealousy, witchcraft is understood as having the capacity to control every aspect of one's life. One participant provided an insight that shows that positive attributes such as beauty are also seen to be the result of witchcraft:

"When you very pretty ... they say ... they hit you when the blood come out she drink the blood she suck it she suck it she suck it ... they say that girl came out pretty, pretty, pretty and she came to the place by the rank [taxi rank] the people say that girl is so pretty."

Witchcraft therefore provides a coherent ideology for daily living and it seems that any and every experience can be attributed to bewitchment. The attributing of all experiences in daily living to witchcraft it seems, is primarily motivated by jealousy. Jealousy as a motivating factor for witchcraft was identified in several conversations:

"Moloi is like a jealous person ... when I am jealous with you then at night when you sleep I do all my things ..."

"Sometimes the neighbours can do witchcraft others because of your children are too cute or successful or I just don't like you so I just want to witchcraft you."

"... you know moloi neh ... is full of jealous."

"For instance with black people we can marry two wives where maybe to find the first wife or the kids don't like the second wife or the kids or maybe there are two sisters and the one sister's children are successful then the other will be jealous."

Witches were also believed to use an array of fantastical means to achieve their goals. This was similar to understandings in the literature that witches, or the 
users of magic, employ supernatural elements in achieving their goals (Burne, 1914; Hole, 1939).

"Moloi can always when you sleep when you dream something that's how it come into you they sent this like err when they take the bread and biscuit and go on top of bread it is like a taxi for them and the biscuit it's like a wheel and they fly."

"Isigiso you are sleeping but eat at the same time and you get sick the medical doctors can't see anything."

"You can get swollen feet they make you sick they can send the lightning to you or like when you are pregnant they will pick up the sand where you walked and you will suffer when you are delivering."

"You know Yaseen this moloi comes to your house they come inside from the door but you don't hear it they turn around and they make the sounds [points to behind] and the door open."

"My grandmother told me a story of a black cat that came into her house she threw hot water [the] next day this old lady came and asked her why she burnt her."

"She can fly she takes the broom and she [gestures a flying motion] ... and she fly to somebody."

Another example of a fantasy description was that of the tokoloshe. In a similar fashion to zombies, who can be used by witches to harm others (Ashforth, 2000), the tokoloshe too, was understood as being created by witches.

"Even the tokoloshe they make the tokoloshe ... they say they making hole and they make the pap [maize porridge] and they take the body parts from the dead people they make like a pop like a doll and they say he grow like how the flower he grow they know for how long they putting it there [in the ground] now they take it out and they give the name."

"They [witches] send a tokoloshe to your house. It can translate and tell the person the life you are living you can't see it they can see it ... it can sleep with you so it takes away feeling from your husband ..."

"They see I got good life so they sent tokoloshe he is sleeping with me ..." 
Witchcraft as described and understood by participants has the capacity to influence every aspect of one's life. The manner of achieving these aims is steeped in a tradition that associates witchcraft with fantasy and the supernatural.

It thus seems that any misfortune experienced within these domains, may provide people with an opportunity to deflect self-blame and responsibility towards the intentions of jealous persons, who utilise witchery. Ashforth (2000) and others (Simmons, 1990; van Dyk, 2001) support this by concluding that witchcraft is believed to be responsible for almost any and every experience while, Evans-Pritchard (1937) described witchcraft as an explanation for what may be deemed, undeserved misfortunes.

This feeds into the notion of witchcraft beliefs as a means to attribute success - not to hard work, genetics or good fortune - but rather to the evil work of the Devil and witchcraft. In essence this takes away the social standing of an individual who has achieved success and an explanatory framework that maligns them is created.

Witchcraft beliefs in South Africa also appear to draw strength, paradoxically, from what is communicated in traditional Christian churches where witchcraft is portrayed as the antithesis of conventional religion. This became apparent when participants spoke about protecting oneself from bewitchment. Below are some excerpts from various conversations.

"If I leave the Church the tokoloshe [will] kill me."

"A moloi can fly ... from here to Mozambique that's how I heard from the Church."

"Especially [if] you don't pray you can be a very scared you can't even say moloi moloi is like even if you say tokoloshe and you don't pray you can't say tokoloshe once you say tokoloshe at night he come."

Given the centrality of African cultural and Christian religious beliefs in the lives of many, it follows that if witchcraft is defined as a real phenomenon, within these domains it will influence the thinking, behaviour and actions of people.

\section{The fear of witchcraft (bewitchment)}

Through conversations with participants, the fear of bewitchment became evident. Participants often stated "this witchcraft thing is dangerous" and that studies to understand it should not be pursued. Alternatively, participants were shocked at the topic and refused to participate. Others, laughed, but when prompted into a conversation, provided fascinating insights into the belief. 
In this paper, it is argued that fear of witchcraft is derived from its perceived capacity to cause harm. This is supported by Oliver (1928) who inform us that witchcraft embeds fear in those who believe in it. In fact, most descriptions of witchcraft, including photographic depictions, reproduce the image of witchcraft in association with fear.

A specific example to highlight fear was obtained from a participant who agreed to provide me with information. However, due to a thunderstorm that occurred after my initial conversation with her, she became very reluctant to speak to me, convinced that witches can send lightning to kill people. She said: "I hope they [witches] don't come for me tonight."

Other participants explained how accusations of witchcraft and fear of bewitchment increases distrust among community members, breaking down social cohesion amongst neighbours, friends and even within families.

"... once someone said you are the witch no one will want to come close to you because you will they will everybody will [be] scared of you because they will you know it is not a good thing it is an evil thing it is not right at all ... the community is afraid, people will be afraid. There is this lady an old lady she is a moloi. When she walks on this side of the street, you walk on the other side."

With an understanding that positive interpersonal relations and trust, an increase in social cohesion is experienced; it can be stated that once an accusation of witchcraft has been made, distrust amongst community members spreads. Colleta \& Cullen (2000: 4) state that "the weaker the social cohesion, the weaker the reinforcing channels of socialization and social control". This is based specifically on the fear of bewitchment and as a result, trust and relationships amongst neighbours, friends and even within families begins to breakdown. Golooba-Mutebi (2005) indicates that if accusations of witchcraft are made, trust amongst friends and neighbours decreases. In this way then, social cohesion begins to break down as the trust between people is compromised.

The breakdown in social cohesion brings the expression of what Putnam (1993) called bonding form of social cohesion. Here, like-minded individuals create an in-group and exclude anyone that may threaten their well-being. The formation of gangs then could be explained as forming as a consequent to the breakdown in social cohesion. Similarly, mob-based attacks on those accused of witchcraft may be the manifestation of the breakdown in social cohesion. The violence, is the end result of conflict that develops when the networks and connections between people are compromised. 


\section{Violence and witchcraft accusations}

When asked what should be done to those who were identified as witches, participants said:

"Kill them because they are not a good people to live with, they ruin your life."

And,

"The community they do horrible things they are burnt and stabbed the whole family."

These responses reflect the commonly held notion, that once an accusation of witchcraft has been made, violence is likely to follow (Barstow, 1995; Levack, 1995). One participant informed me that in Limpopo province he witnessed several violent attacks with accused witches.

Interviewer: "Ok so you got the moloi out of the house and what did you say?"

Participant: "We first ask her are you the moloi yeah then she say l'm a moloi okay tell us what you did I did 123 to Letti she tell us and we tell her okay tell us we won't do anything to you."

Interviewer: "You won't do anything?"

Participant: "Nothing then she tells us."

Interviewer: "So you promise her that she will be okay."

Participant: "So she saying everything I did this I did this and you know that men who passed away haai he never passed away I got him in the yard."

Interviewer: "Okay."

Participant: "Ok then she show us we want him okay we can find him okay so it's better we kill you now."

Interviewer: "So you kill her?"

Participant: "Yeah."

Interviewer: "How would you kill her?" 
Participant: "Haai is the gang so someone can take the stone or the stick the rope the fire and then we put the fire the diesel and burn them."

Given the fear of bewitchment, it follows that avoidance of, or more so, the eradication of this threat is needed in the witchcraft paradigm, which may be a possible reason as to why large groups of people may attack an accused; as they are afraid of bewitchment and the breakdown in supportive networks becomes the breeding ground for further suspicion, distrust and conflict.

In another conversation, participants debated witchcraft violence. This conversation is important, because participants began speaking about protecting the witch.

Participant (A): "Hey but you can't just say that you are going to kill people it is a crime"

Participant (D): "It is very difficult to decide on this because if we leave them [accused] they they will harm us again but if you kill them then the police will come for you."

However, as the conversation continued, they alluded to the fact that killing a witch is the best solution.

Participant (A): "They must take her to the police ... they must lock the witch up."

Interviewer: "Don't they kill her?"

Participant (A): "Ifyou kill her it's another problem."

Interviewer: "So they can kill her"

Participant (A): "Yes they can kill her but they must not do it in front of the police."

Interviewer: "What will the police do?"

Participant (A): "The police they can do nothing because when the community is cross the community is cross."

It is important to keep in mind that this discussion supports the argument that fear of bewitchment begins the process of a breakdown in social cohesiveness. It is argued by Colletta and Cullen (2000) that weak social cohesion increases 
social disorganisation, exclusion and fragmentation, which ultimately manifests in violent outcomes. Golooba-Mutebi (2005) explores this understanding of the breakdown of social cohesion within communities due to the fear of bewitchment. He states that there will be a lack of consensus in the decision of what needs to be done to the accused. Some communities will support the violence while others will question it. Explicit here, is that once an accusation is made, the fear of bewitchment is the starting point to the breakdown of linkages and networks. In this context the violent consequences met by those accused may be understood as a necessity that protects the survival of 'good' against 'evil'. Within contexts where the belief in witchcraft is subscribed by religion and culture and that the belief itself is fear-based, violence may be the only action known to the community in their treatment of witchcraft. Rose (1982) explains this further by arguing that the threat posed by "evil-doers" like witches, creates the condition to mobilize violent action against them.

The above section discussed results from conversations and focus group discussions held with community members on witchcraft. The purpose of this was to demonstrate the nature of belief in witchcraft in current South African communities. It became evident that witches are believed to be responsible for misfortunes faced and that jealousy is a motivating factor. Fantasy descriptions of witchcraft were provided by participants and this fed into the general fear most of the participants held regarding bewitchment. The fear of bewitchment escalates in most cases towards violent behaviour. The violence faced by accused witches stems from the belief that they have caused harm, havoc or destruction to someone around them or the community at large. Violence in this context may be considered an appropriate means of treatment for those accused of witchcraft.

\section{Conclusion}

This paper located witchcraft beliefs within the perspective of South African community members. Community members' witchcraft beliefs firstly indicated that witchcraft is a significant dimension in these participants' lives and that secondly witches are believed to have the capacity to cause an array of socio-psychological misfortunes. These coupled with the fantasy descriptions provided of witchcraft feeds into the fear of bewitchment. Emanating from the fear of witchcraft, is a decrease in social cohesion, which leads to an increase in distrust and conflict. It was argued that the fear of bewitchment manifests in violent behaviour against those who are accused as a result of the breakdown of important linkages and networks that occurs when witchcraft accusations are made. 


\section{References}

Abdussalam-Bali W (2004) Sword against black magic and evil magicians. New Delhi: Al-Firdous Books.

Ashforth, A (2005) Muthi, medicine and witchcraft: Regulating 'African science' in post-apartheid South Africa? Social Dynamics, 31(2), 211-242.

Ashour, M (1993) The JINN in the Qur'an and the Sunna. London: Dar Al Taqwa Ltd.

Babbie, E \& Mouton, J (2005) The practice of social research. Cape Town: Oxford University Press.

Banyard, V L \& Miller, K E (1998) The powerful potential of qualitative research for community psychology. American Journal of Community Psychology, 26(4), 485-505.

Beauvis, C \& Jenson, J (2002) Social cohesion: Updating the state of the research.

Canada Policy Research Networks, Discussion paper no. F22.

Baroja, J C (1964) Magic and religion in the classical world, in Marwick, M (ed) (1982) Witchcraft. London: Penguin Press.

Barstow, A L (1994) Witchcraze: A new history of the European witch hunts. San Francisco: Pandora.

Bourdieu, P (1986) The forms of social capital, in Richardson, J (ed) (1986) Handbook of theory and research for the sociology of education. New York: Greenwood Press.

Bornman, E, van Eeden, R \& Wentzel, M (1998) Violence in South Africa: A variety of perspectives. Pretoria: HSRC.

Briggs, $R$ (2002) Witches and neighbours: The social and cultural context of European witchcraft. Oxford: Wiley- Blackwell Publishers.

Burne, C S (1914) The handbook of folklore. London: Sigdwick \& Jackson, Ltd.

Colleta, N J \& Cullen, M L (2000) The nexus between violent conflict, social capital and social cohesion: Case studies from Cambodia and Rwanda. Social Capital Initiative, Working Paper No. 23. 
Coleman, J (1990) Foundations of social theory. Cambridge, MA: Harvard University Press.

Comaroff, J \& Comaroff, J L (1999) Occult economies and the violence of abstraction: Notes from the South African post colony. American Ethnologist, 26(2), 279-303.

Dayton-Johnson, J (2003) Social capital, social cohesion, community: A microeconomic analysis, in Osberg, $\mathrm{L}$ (ed) The economic implications of social cohesion.

Toronto: University of Toronto Press.

Douki, S, Nacef, F, Bekhadi, A, Bouasker \& Ghachem, R (2003) Violence against women in Arab and Islamic countries. Archives of Women's Mental Health, 6(3), 165 -171.

Dein, S (2003) Psychogenic death: Individual effects of sorcery and taboo violation. Mental Health, Religion and Culture, 6(2), 195-202.

Eldam, A E (2003) Tendency of patients towards medical treatment and traditional healing in Sudan. PhD dissertation. University of Oldenburg, Germany.

Evans-Prichard, E E (1937) Witchcraft, oracles and magic among the Azande. Oxford: Faber and Faber.

Fisiy, C \& Geschiere, P (1991) Domesticating personal violence: Witchcraft, courts and confessions in Cameroon. Africa: Journal of the international African institute, 64(3), 323-341.

Fortes, M (1953) The structure of unilineal descent groups. American Anthropologist, 55(1), 17-41.

Golooba-Mutebi, F (2005) Witchcraft, social cohesion and participation in a South African village. Development and Change, 36(5), 937-958.

Greenwood, N, Hussain, F, Burns, T \& Raphael, F (2000) Asian in-patient and carer views of mental health care. Asian views of mental health care. Journal of Mental Health, 9(4), 397-408.

Hansen, C (1969) Witchcraft at Salem. New York: George Braziller.

Harwood, A (1970) Witchcraft, sorcery and social categories, in Marwick, M (1982) Witchcraft. London: Penguin Books. 
Heinemann, E (2000) The psychoanalytic exploration of the killing of women. London: Free Association Press.

Henning, E (2004) Finding your way in qualitative research. Pretoria: Van Schaik Publishers.

Hole, C (1940) English Folklore. London: Batsford Ltd.

Igwe, L (2004) A skeptical look at African witchcraft and religion. The Skeptic, 11(1), 72-75.

Ivey, G \& Myers, T (2009) The psychology of bewitchment (Part I): A phenomenological study of the experience of bewitchment. South African Journal of Psychology, 38(1), 54-74.

Joshi, P C (2000) Relevance and utility of traditional medical systems (TMS) in the context of a Himalayan tribe. Psychology in Developing Societies, 12(5), 6-29.

Kgosana, C (2007) Sexwale slams COPE for using witchcraft. IOL News. http://www.iol. co.za/news/politics/sexwale-slams-cope-for-using-witchcraft-1.432299.

Date retrieved 12 June 2013.

Larner, C (1974) Is all witchcraft really witchcraft? London: Penguin Books.

Levack, B P (1995) The witch hunt in early modern Europe. London: Longman Group Limited.

Lin, N \& Erickson, B H (2008) Social capital: An international research program. Oxford: Oxford University Press.

Maxwell, D (1995) Witches, prophets and avenging spirits: The second Christian movement in North-East Zimbabwe. Journal of Religion in Africa, 25(3), 309-339.

McNab, C (2007) Mythological monsters. New York: Scholastic, Inc.

Meyer, W, Moore, C \& Viljoen, H (2003) Personology: From individual to eco-system (3rd ed). Cape Town: Heinemann.

Miguel, E (2005) Poverty and witch killing. Review of economic studies, 72(4), 1153-1172.

Mkhize, N (2004) Psychology: An African perspective, in Hook, D (ed) Critical psychology. Cape Town: UCT Press. 
Morton-Williams, P (1960) The Yoruba Ogboni cult in Oyo. Africa, 30(4), 362-374.

Moore, H L \& Sanders, T (2002) Magical interpretations, material realities:

Modernity, witchcraft and the occult in post-colonial Africa. London: Routledge.

Mpumalanga Witchcraft Suppression Act (1957) South African Law Reform Commission. http://www.justice.gov.za/salrc/ipapers/ip29-prj135-Witchcraft-2014.pdf.

Date retrieved: 15 April 2015.

Niehaus, I (2000) Towards a dubious liberation: Masculinity, sexuality and power in the South African Lowveld schools, 1953-1999. Journal of Southern African studies, 26(3), 387-407.

Oliver, C W (1928) An analysis of magic \& witchcraft: A retrospective introduction to the study of modern metapsychics. London: Rider Publishing.

Parrinder, G (1963) Witchcraft: European and African. London: Faber \& Faber.

Peltzer, K \& Renner, W (2003) Superstition, risk-taking and risk perception of accidents among South African taxi drivers. Accident, Analysis and Prevention 35(4), 619-623.

Putnam, R (1993) Making democracy work: Civic tradition in modern Italy. Princeton: Princeton University Press.

Putnam, R D (2000) Bowling alone: The collapse and revival of American community. New York: Simon and Schuster.

Rose, E (1982) A razor for a goat. Toronto: University of Toronto Press.

Roy, P (1998) Sanctioned violence: Development and persecution of women as witches in South Bihar. Development in Practice, 8(2), 136-147.

Simmons, W S (1980) Powerlessness, exploitation and the soul-eating witch: An analysis of Badyaranke witchcraft. American ethnologist, 7(3), 447-465.

Stafford, B (2005) The growing evidence for 'demonic possessions': What should psychiatry's response be? Journal of Religion and Health, 44,(1) 13-30.

Stark, R (2003) For the glory of God: How monotheism led to reformations, science, witch-hunts and the end of slavery. London: Princeton University Press. 
Swartz L (1998) Culture and mental health: A southern African view. Cape Town: Oxford University Press.

Van Dyk, A (2001) HIV/AIDS: Care and Counselling. Johannesburg: Kagiso Higher Education.

Webster, H (1932) Magic: A sociological study. New York: Octagon Books. 